\title{
Are we there yet?
}

\author{
by Paul McKellips
}

When I was a young child, my parents took me on the annual pilgrimage to Florida to enjoy a short respite from brutal Wisconsin winters. I remember lying in the backseat window deck of my Dad's Buick-on top of the radio speakers-and playing with Matchbox cars and rubber army men for hours on end. Occasional hard braking would only add to the fun, as I went airborne into the back seat just like Batman. Fortunately, I never got hurt on those nasty seat-belt buckles because they were purposely buried deep inside the seat cushion so we wouldn't have to sit on them and be uncomfortable.

When I grew a bit older, I rode all over town on my bicycle, first a banana bike, then a fancy Schwinn ten-speed, both decked out with baseball cards clipped to the spokes by clothespins. I wore way cool tie-dye t-shirts and cut-off blue jeans, but there was no such thing as a bike helmet that could either be worn or purchased.

By the time my first child arrived in 1992, Uncle Sam had stepped into our daily lives, mandating basic safety measures and regulations. If we didn't 'click it' then there'd be a ticket for safety belt noncompliance. Virtually every cyclist on the planet wore a bike helmet. And unlike my Great Depression and World War II-era parents' carefree attitude towards safety, I practically packaged my children in bubble-wrap to protect them from unthinkable catastrophes that might erupt on them at any moment.

Looking back, I can see how we got here. I'm sure that a committee of Emergency Room physicians had seen enough injuries from kids without seat-belts and riders without helmets. A sympathetic congressman-perhaps with his own tragic experience-probably crafted the legislation, and before too long, government

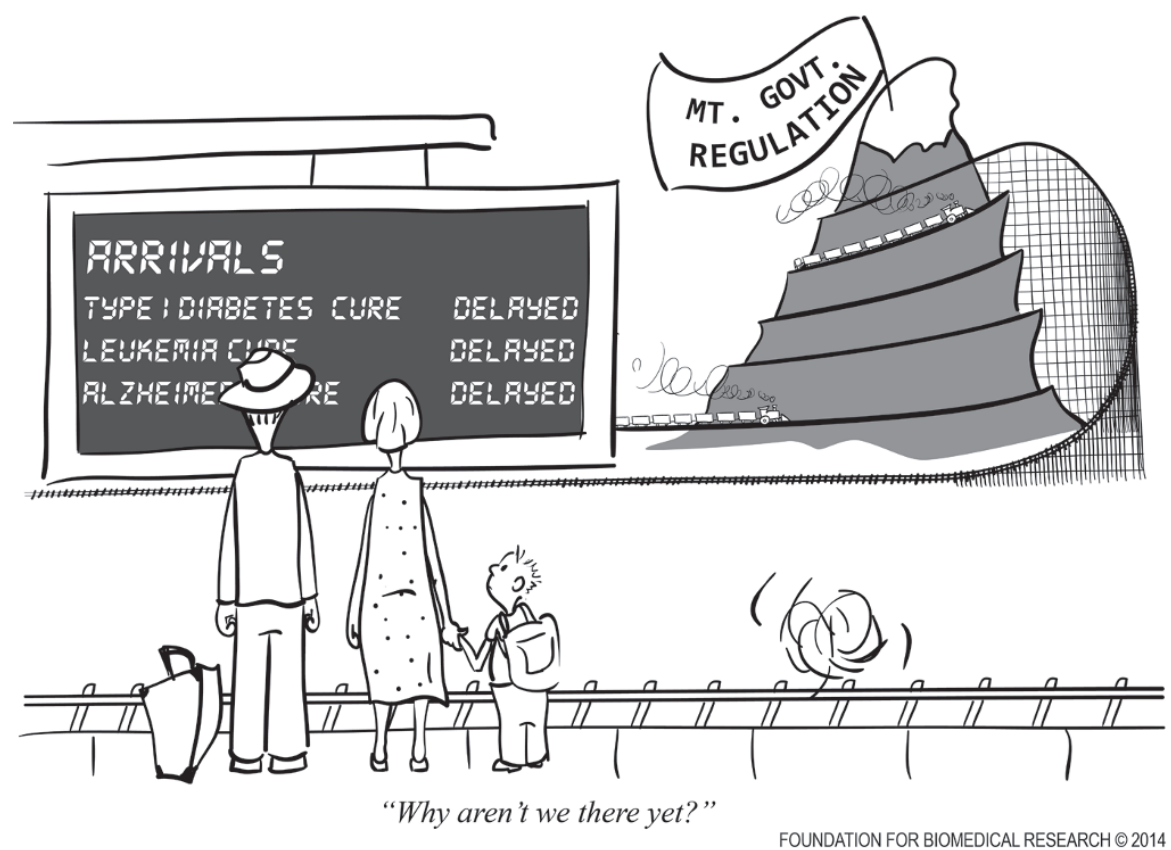

agencies were regulating every aspect of riding a bicycle and manufacturing a helmet. And I'm pretty sure that additional regulations have been added each year in an all-out effort to eliminate all risk.

A sound regulatory framework does, indeed, protect the public and can instill confidence. But what happens when regulations expand to such a point where they become burdensome yet provide no public benefit? Can excessive government regulation inhibit growth? Can it also drive up costs needlessly?

Many regulations for lab animal research are crucial to protect animal well-being and to make sure the process of discovery is consistent. Managers, supervisors, IACUC members and inspectors work tirelessly to make sure our laboratories and vivariums comply with federal standards and regulations.

But at some point the regulatory burden on biomedical research will become excessive. Perhaps we have reached that tipping point now.
Are costly regulations in place that provide no welfare benefit to lab animals but might be preventing potential lifesaving research from moving forward? Are significant funds being diverted away from research in order to achieve compliance with over-reaching regulations? Does this diversion, across the national research enterprise, slow discovery? And is it possible that such a discovery slowdown translates into a longer time to find cures that will ultimately drive down the cost of health care and improve our quality of life?

I fondly remember the Buick's backseat window and my bike spokes clicking with baseball cards, but I'm glad that we have seat-belt laws and bike helmets in multiple colors these days. I'm all for regulations that reasonably protect my children and give me greater confidence.

But if we insist on packing our childrenor the biomedical research industry-in bubble-wrap to prevent any consequence from ever happening, then we'll always be wondering why we're not there yet. 